\title{
Muestreo, instrumentos y aspectos bioéticos de un estudio poblacional en Lima y Callao
}

\author{
Deza Becerra F ${ }^{1}$, Chang Dávila $\mathrm{D}^{2}$ \\ Estudiante de Medicina, Universidad Católica Santo Toribio de Mogrovejo. \\ ${ }^{2}$ Médico General, Docente en Universidad Católica Santo Toribio de Mogrovejo.
}

\section{SEÑOR EDITOR:}

En relación al artículo publicado en la revista Anales de la Facultad de Medicina, volumen 73 número 2, titulado Violencia basada en género en zonas urbanas y urbano- marginales de Lima y Callao, 2007-2010, se aborda un problema de impacto creciente en nuestra sociedad. La violencia conyugal es un problema de Salud Pública en el Perú por sus graves consecuencias de salud, sociales y económicas. Según el INEI en la Encuesta Demográfica y de Salud Familiar 2010, el 38,4\% de las mujeres sufrió violencia física y sexual, cifras que difieren según región geográfica o áreas de residencia ${ }^{(1)}$. Se destaca que en este estudio se haya realizado el análisis según zonas urbanas y urbano- marginales. El artículo proporciona información relevante acerca de la violencia contra la mujer en nuestra realidad peruana. Sin embargo, cabe señalar algunos aspectos metodológicos. Se describe que la población a estudiar son un grupo de mujeres, sin embargo, no se delimitan las edades y los criterios de exclusión están poco claros; es un hecho que no se incluye a los varones. En cuanto al tipo de muestreo, se menciona muestreo por manzanas, por lo que se entiende que se realizó un muestreo por conglomerados, pero no se habla acerca del cálculo de la muestra por algún programa estadístico.

Se describe adecuadamente cuáles son las variables a estudiar, violencia física, psicológica, económica y sexual, pero no su definición operacional. Para recoger la información se confeccionó y aplicó un formulario, sin embargo no hay detalles acerca del instrumento usado, como su validación y confiabilidad. Existen diversas escalas para medir violencia contra la mujer, el Index of Spouse Abuse o Índice de Abuso al Cónyuge está validada al español, pero no hay adaptación a la población peruana ${ }^{(2,3)}$; el Severity of Violence Against Woman Scale; en el 2006, se construyó en México una Escala de Violencia que demostró ser un instrumento útil y confiable para medir la violencia masculina ejercida en las relaciones de pareja ${ }^{(4)}$. La escala más usada es la Conflict Tactics Scale (CTS) o Escala de Tácticas para los Conflictos, usada desde 1972; el CTS2, que es una versión revisada del CTS original, está constituido por 5 subescalas: negociación, ataque psicológico, ataque físico, coerción sexual y daño físico, existe una versión modificada al español realizada en el $2007^{(5)}$.

En el estudio se menciona que se inició la entrevista luego del consentimiento verbal. Como se sabe, cualquier estudio realizado debe antes ser evaluado por un comité de ética y construir un consentimiento informado, el cual debe ser firmado por el participante antes de iniciar la entrevista. Tratándose de un estudio poblacional en Lima, la metrópoli del Perú, donde se encuentra el mayor número de habitantes y vien- do las alarmantes cifras de violencia encontradas, resalta la no mención de algunas propuestas o esfuerzos por hacer que estos índices disminuyan.

\section{REFERENCIAS BIBLIOGRÁFICAS}

1. Instituto Nacional de Estadistica e Informática (INEI). Capitulo 12: Violencia contra la mujer, niñas y niños en Perú [Internet]. En: Encuesta Demográfica y de Salud familiar 2010. Lima: INEI; 2011 [citado el 6 de febrero 2012]. Disponible en: http://proyectos.inei. gob.pe/endes/en des2010/resultados/index.html.

2. Torres A, Navarro P, Garcia-Esteve L. Tarragona MJ, Ascaso C, et al. Detecting domestic violence: Spanish external validation of the Index of Spouse Abuse. [Internet] 2010. J Fam Viol. 2010;25:275-86. [citado 25 octubre 2012]. Disponible en: http:// empower- daphne.psy.unipd.it/userfiles/file/pdf/Tor res\%20A_\%20-\%202009.pdf

3. Sierra JC, Monge F, Santos P, Bermúdez M, Salinas J. Validation of a reduced Spanish version of the Index of Spouse Abuse. [Internet] Int J Clin Health Psychol. 2011;11(2):363-83. [citado 25 octubre 2012]. Disponible en: http://www.aepc.es/ijchp/ articulos_pdf/ij chp-384.pdf

4. Valdez-Santiago R, Hijar-Medina MC, Salgado de Snyder VN, Rivera-Rivera L, Avila-Burgos L, Rojas R. Escala de violencia e indice de severidad: una propuesta metodológica para medir la violencia de pareja en mujeres mexicanas. [Internet]. Salud Pública de México. 2006;48(2):221-31. [citado 25 octubre 2012]. Disponible en: http://www.scielosp. org/pdf/spm/v48s2/31378.pdf

5. Muñoz-Rivas M, Andreu JM, Graña JL, O'Leary DK, González MP. Validación de la versión modificada de la Conflicts Tactics Scale (M-CTS) en población juvenil española. [Internet]. Psicothema. 2007;19(4):693-98. [citado 25 octubre 2012]. Disponible en: http://www.unioviedo.net/reunido/index. php/PST/article/view/8537/8401

Correspondencia:

Fátima Deza Becerra

Correo electrónico: fatima_deza17@hotmail.com 


\section{LA CARTA AL EDITOR FUE REMITIDA A LOS AUTORES DEL ARTÍCULO EN REFERENCIA, OBTENIÉNDOSE LA SIGUIENTE RESPUESTA.}

\section{Respuesta a Carta al Editor. Violencia basada en género en zonas urbanas y urbano-marginales de Lima y Callao, 2007 - 2010}

Los estudios epidemiológicos ${ }^{(1)}$ requieren para el proceso de estratificación y presentación de la información de las variables intervinientes como el estado civil, nivel educativo, la procedencia, entre otros, por lo que consideramos que la edad también sería necesaria, y la hemos presentado en la tabla 1 del artículo. Generalmente en los estudios de recolección de muestras por viviendas, existe la mayor posibilidad de encontrar a las madres y sus hijos en los hogares, y usualmente los padres no se encuentran en horas de trabajo, por lo que se consideró excluirlos del estudio, lo cual se encuentra descrito en la sección material y métodos del estudio. La determinación de la muestra ${ }^{(2,3)}$ está en correspondencia en la confianza requerida, la varianza del fenómeno y la precisión deseada; inicialmente, es decir, en los primeros años, se calculó un tamaño de muestra tomando en consideración una precisión del 5\% y una confianza del $95 \%$ y como no se tenía evidencia de la varianza de la violencia basada en género en zonas urbanas de Lima, se aplicó la prevalencia máxima, lo cual determinó una muestra de 384 participantes. Pero, las muestras están determinadas no solamente por los elementos indicados, sino también con los recursos humanos y materiales para la recolección, lo cual fue cubierto en más de lo previsto por el apoyo de los estudiantes de obstetricia de la universidad; razón por la cual, la muestra presentada consideramos consistente y representativa. La determinación de los instrumentos de recolección ${ }^{(4)}$ de datos está supeditada a las dimensiones que se quiere medir. La presente investigación tomó la información oficial del sector salud, para determinación de casos de violencia, y se agregaron a ellas las variables restantes, lo que consideramos es consistente con otros elementos que definen los mismos eventos que hemos medido.

\section{REFERENCIAS BIBLIOGRÁFICAS}

1. Varkevisser C, Pathmanathan I, Brownlee A. Diseño y realización de proyectos de investigación sobre sistemas de salud. Volumen 2 Parte 1. 1995.

2. Briones G. Metodologia de la investigación cuantitativa en ciencias sociales. ARFO Editores. 2002.

3. Tamayo M. La investigación. Módulo 2 Serie Aprender a investigar. ICFES 3ra. Ed. 1999.

4. Pineda E, Alvarado E, Canales F. Metodologia de la investigación. $2^{\circ}$ Edic. Edit. OPS/OMS. 1994. 